\title{
Growth of $E$. coli BL21 in minimal media with different gluconeogenic carbon sources and salt contents
}

Thusitha S. Gunasekera • Oleg Paliy

Published online: 14 November 2006

(C) Springer-Verlag 2006

The online version of the original article can be found at: http://dx.doi. org/10.1007/s00253-006-0554-8.

T. S. Gunasekera $\cdot$ O. Paliy $(\bowtie)$

Department of Biochemistry and Molecular Biology,

Wright State University,

256 BioSciences, 3640 Col. Glenn Hwy,

Dayton, OH 45433, USA

e-mail: oleg.paliy@wright.edu
The original version of this article unfortunately contained a mistake. The sequence of the author names was incorrect. The correct sequence is given above. 